\title{
FLOATING BREAKWATERS AS PUBLIC PLATFORMS - IMPACT ON POSTURAL STABILITY
}

\author{
Elizabeth Freeman, Water Research Laboratory, UNSW Sydney, elizabeth.freeman@student.unsw.edu.au \\ Dr Kristen Splinter, Water Research Laboratory, UNSW Sydney, k.splinter@unsw.edu.au \\ Dr Ron Cox, Water Research Laboratory, UNSW Sydney, r.cox@unsw.edu.au
}

\section{BACKGROUND}

Floating Breakwaters are used extensively to provide cost effective protection from wind and vessel waves. Floating breakwaters are commonly multitasked, being used as a point of mooring for vessels or simply an access way to other pontoons in a small boat harbour, as well as their main function as wave dissipators.

A floating breakwater does not completely stop the incident wave; rather it partially transmits, partially reflects and partially dissipates the wave energy. Cox et al (2007) completed wave flume testing of a number of floating breakwaters and reported on performance in irregular waves with particular emphasis on wave transmission and reflection, energy dissipation and restraining forces. Motion measurements were limited by the instrumentation.

This paper discusses the results from a further series of laboratory experiments on the dynamic motions of an active floating breakwater system. The performance is related to wave attenuation, wave reflection and energy dissipation as well as safety considerations for standing persons based on high resolution measurements of accelerations in all six degrees of freedom.

\section{MODEL TESTING}

Model testing of a floating breakwater subject to regular waves has been undertaken and the dynamic motion data recorded in the form of accelerations. Incident and transmitted wave heights have been logged to ascertain the effectiveness of the floating breakwater in attenuating the incident waves.

The floating breakwater tested was a rectangular prism with six degrees of freedom: surge (longitudinal, $x_{b}$ ), sway (lateral, $y_{b}$ ) and heave (vertical, $z_{b}$ ), as well as the three rotations around the centre of gravity (roll $(\phi)$, $\operatorname{pitch}(\theta)$ and yaw $(\psi))$. The breakwater was restrained by its piles, however there was still enough play in the pile brackets as well as deflection in the piles that acceleration due to translation in the $\mathrm{x}$ and $\mathrm{y}$ direction was relevant. The model was constructed to have uniformly distributed internal ballast over the plan area in order to achieve desired buoyancy and freeboard based on the prototype being tested.

Motion data were recorded using five, six-axis Inertial Measurement Units (IMUs) positioned centrally and on the corners of the breakwater model. Simultaneously, data from the wave probes was recorded. Wave statistics for each probe location were then calculated using the Matlab software package based on the recorder time series of water level data. Wave data and associated accelerations and rotations were then analysed.

\section{RESULTS}

Data collected and analysed includes the dynamic motions of the floating breakwater in the form of the three translations and three rotations in and about the $\mathrm{x}, \mathrm{y}$ and $z$ axis. These motions are compared with motion limits nominated in various codes/standards to ensure a standing person is comfortable and stable. Results indicate vertical and lateral accelerations up to six times higher than what would be perceived as safe/comfortable.

Results on the incident and transmitted wave heights show that wave attenuation is highest when the wave and breakwater interactions produce high wave reflection and/or high energy dissipation. The effectiveness of the structure has been quantified by determining the transmission coefficient $(K)$, calculated by dividing the transmitted wave height by the incident wave height. Results show that for the breakwater tested the highest attenuation occurs when the structure exhibits the greatest level of dynamic motion, accelerations as high as $0.688 \mathrm{~g}$ (vertical) with a transmission coefficient of approximately 0.207 .

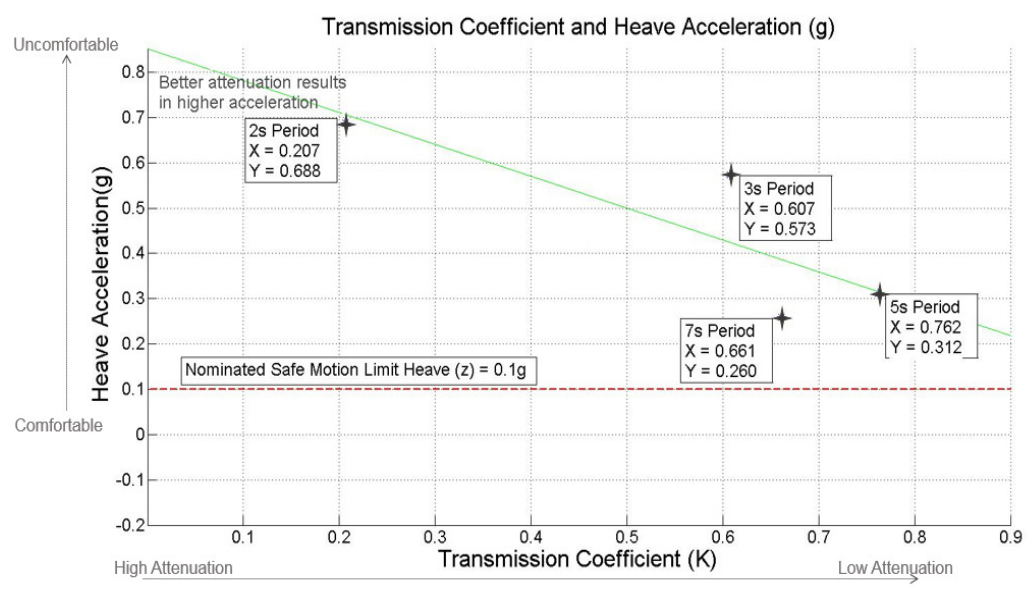

Figure 1. Transmission coefficient $(\mathrm{K})$ versus heave ( $z$ axis) acceleration $(g)$. The red dashed line shows the nominated safe motion limit for vertical acceleration $(0.1 \mathrm{~g})$. All tested wave periods $(2-7$ second prototype) had vertical accelerations above the safe motion limit. The graph shows best attenuation occurs when the floating breakwater undergoes the highest accelerations. Mean wave heights tested ranged from $200-300 \mathrm{~mm}$ prototype wave height.

\section{REFERENCES}

Cox R, Coghlan I and Kerry C., 'Floating Breakwater Performance in Irregular Waves with Particular Emphasis on Wave Transmission and Reflection, Energy Dissipation, Motions and Restraining Forces'. Coastal Structures Conference, Venice, 2007. 